\title{
Digitalizacion y efecto enjambre. Comunicación, General Intellect y poder en el semiocapitalismo
}

Digitalization and swarm effect. Communication, General Intellect and power in semiocapitalism

Digitalização e efeito enxame. Comunicação, Intelecto Geral e poder no semiocapitalismo

Victor LENARDUZZI CORREO

Universidad de Buenos Aires (Argentina)

victorlenarduzzi@gmail.com

Gabriela SAMELA

Universidad de Buenos Aires (Argentina)

gsamela@gmail.com

Chasqui. Revista Latinoamericana de Comunicación

N.o ${ }^{\circ}$ 48, diciembre 2021 - marzo 2022 (Sección Diálogo de saberes, pp. 279-294)

ISSN 1390-1079 / e-ISSN 1390-924X

Ecuador: CIESPAL

Recibido: 28-o9-2021 / Aprobado: 12-11-2021 


\title{
Resumen
}

Este trabajo propone un acercamiento al problema del efecto enjambre en la comunicación contemporánea a partir de la obra de Franco Berardi, en diálogo con otros autores. Para ello se presentan sus aportes respecto de la comunicación, el semiocapitalismo y la gobernanza. Luego, se discute la idea de una "inteligencia colectiva" como potencial de creatividad y libertad a partir de la noción de generall intelect (Marx, Virno, Berardi). A partir de esta cuestión, abordamos el tema "enjambre" como la deriva de la cultura digital contemporánea y sus articulaciones con los conceptos de red y multitud.

Palabras claves: conjunción; automatismo; gobernanza; multitud

\begin{abstract}
This work aims to approach the problem of the swarm effect in contemporary communication based on the work of Franco Berardi, in dialogue with other authors. First, we present their contributions about communication, semio-capitalism and governance. Then, we confront the idea of a "collective intelligence" as potential for creativity and freedom with the notion of general intellect (Marx, Virno, Berardi). Finally, we consider the swarm as the drift of contemporary digital culture and its articulations with the concepts of "net" and "multitude".
\end{abstract}

Keywords: conjunction; automatism; governance; multitude

\section{Resumo}

Este trabalho aborda a problemática do efeito enxame na comunicação contemporânea a partir da obra de Franco Berardi, em diálogo com outros autores. Primeiro, apresentamos suas contribuições sobre comunicação, semiocapitalismo e governança. Em seguida, confrontamos a ideia de uma "inteligência coletiva" como potencial de criatividade e liberdade com a noção de intelecto geral (Marx, Virno, Berardi). Finalmente, consideramos a questão do enxame como a deriva da cultura digital contemporânea e suas articulações com os conceitos de rede e de multidão.

Palavras-chave: conjunção; automatismo; governança; multidão 


\section{1-Introducción}

Las transformaciones de la sociedad contemporánea -si se va más allá de la inmediatez característica del discurso celebratorio del avance técnico-, pueden inscribirse en procesos de diferente alcance. En una conversación publicada en 1981 en Filosofía radical, el filósofo Herbert Marcuse advertía:

Desde aproximadamente 1968-1969 puede hablarse de una nueva fase de represión intensificada en los países capitalistas avanzados, pero no sólo en los países capitalistas, sino aún más en las regiones del Tercer Mundo. Asistimos a la racionalización de lo irracional. A los medios y posibilidades ya existentes de amordazamiento, desmoralización y control de la población, se ha añadido un nuevo elemento. Un elemento extraordinariamente relacionado con el nivel del progreso técnico, con la computarización, con el perfeccionamiento técnico de la recogida de datos y de la vigilancia. (2018: p.167)

Esto resulta interesante visto en perspectiva, ya que hoy podemos ver realizadas muchas estrategias de control y vigilancia técnicamente producidas que -paradójicamente- son experimentadas como un entorno de libertad y expresividad. Es decir, aquello que allí aparecía como una tendencia en la actualidad es una realización expandida por el planeta.

Retomar a Marcuse para pensar la actualidad no es algo arbitrario. Franco Beradi considera que Marcuse -sobre todo el de El hombre unidimensionalha sido un autor fundamental para comprender cómo a partir del desarrollo científico-técnico se terminaron consolidando formas instrumentalizadas del conocimiento, operativización del lenguaje y la comunicación, automatización de la vida colectiva y estrategias de control social (Marcuse, 1968: p. 25-26; Berardi, 2019, p. 222-224). En las últimas décadas se ha producido una profunda modificación de las formas de comunicación y de la producción cultural. La misma se vincula con el lugar central que las tecnologías digitales han adquirido en las formas de intercambio simbólico, sea en la interacción en la vida cotidiana o en la comunicación de gran alcance. Esto se suele describir como un desplazamiento, como un pasaje de los medios masivos a las redes digitales que redefinieron el paisaje mediático como un conjunto. En ese marco, las tradiciones teóricas que permitieron pensar a la cultura y los medios masivos, si bien no pierden toda vigencia en sus formulaciones, resultan insuficientes para captar la profundidad de la metamorfosis en curso y necesitan abrirse a nuevas conceptualizaciones.

Los cambios, visibles y evidentes, no son tan recientes pero parecen haberse acelerado de forma decisiva en las primeras décadas del siglo XXI para desbordar lo comunicacional y terminar afectando al conjunto de la existencia. El crítico Éric Sadin observa con agudeza que "Internet no constituye de ahora en más sino un parte relativa del entorno digital que ha desbordado el estricto marco frontal de la pantalla para conquistar progresivamente todos los campos 
de la vida" (Sadin, 2018: p.36). Se trataría de asumir que desde la década de 2010 el "momento internet" y la "era del acceso" a la información y la comunicación conviven con una nueva fase que se desarrolla de manera simultánea y que se puede describir como "la era de la medición de la vida" (Ídem: 37 ).

En este artículo nos proponemos recuperar algunas claves teóricas para pensar estos cambios poniendo énfasis en los aportes formulados por Franco Berardi (aunque en diálogo con otros referentes). Para esto hemos delimitado tres grandes ejes:

- la comunicación y la sintactización en el contexto de la mutación conectiva que se articula en el marco del concepto de semiocapitalismo y en el pasaje hacia la gobernanza como forma de estructuración del poder,

- la mirada crítica sobre la "inteligencia colectiva" y el potencial democrático de la nueva escena tecnológica, a partir de la categoría general intellect,

- la problematización del concepto de multitud, en el contexto de las nuevas relaciones de poder, a partir del "efecto enjambre".

\section{2-Conjunción y mutación conectiva}

Puede ser una obviedad partir de la idea de que la comunicación tiene que ver con la "empatía", con el encuentro con el otro y con la vinculación sensible con los demás. Franco Berardi considera que esto puede conceptualizarse como conjunción, es decir, pensando cómo los seres humanos se relacionan gracias a sus capacidades intelectuales y sensuales. Además, existe

...otro nivel de concatenación, que es el menos estudiado por los sociólogos de la comunicación: la sensibilidad. La sensibilidad es la capacidad de los seres humanos de comunicar cualquier cosa que no se pueda decir con palabras. Es la disponibilidad de los cuerpos a las caricias, a la compasión entendida como percepción compartida. El organismo colectivo es capaz de conjunción y, por tanto, capaz de afectividad, comprensión sensual y solidaridad social. (Berardi, 2014: p.104).

La conjunción, en algún punto, no se ajusta con claridad a un diseño previo, quizá hasta se resiste a esto último. Y es precisamente esto lo que se ha transformado fuertemente en el profundo cambio antropológico que Berardi (2017) denomina "mutación conectiva". Aquí entra en escena un segundo concepto clave para comprender el abordaje de la comunicación actual: la conexión.

La conexión es interacción puntual y repetible de funciones algorítmicas, de líneas de red y de puntos que se solapan perfectamente, se insertan y separan según modalidades discretas de interacción. Modalidades discretas que hacen compatibles entre sí a las diversas partes según estándares predeterminados. (Berardi, 2014: p.107) 
Precisamente, el cambio tiene que ver con el predominio de la conectividad, por una infoesfera y una tecnoesfera que se vuelven más aceleradas y densas. Esto implica que la digitalización "está invirtiendo la manera en que percibimos nuestro entorno y también la manera en que lo proyectamos. No involucra únicamente nuestros hábitos, sino que afecta nuestra sensibilidad y sensitividad" (Berardi, 2017:10). ${ }^{1}$ En síntesis, se trata de un desplazamiento de la conjunción a la conexión como paradigma de las relaciones humanas ${ }^{2}$ que viene siendo tematizado como problema contemporáneo. (Berardi, 2014; Van Djick, 2016; Han, 2014)

Esta caracterización ubica a la comunicación en un lugar básico en la construcción de la vida colectiva, en un lugar primario y estructurante de la sociedad presente. Ahora bien ¿cuál es el marco o encuadre del modo de vida de hoy? ¿Qué es lo que nos permitiría definirlo con precisión? Berardi ha construido un concepto muy esclarecedor, el de semiocapitalismo, que apunta a dar cuenta de una suerte de naturaleza semiótica del capitalismo actual en el que tanto el intercambio y la recombinación de signos como la acumulación de datos y el procesamiento de la información se han vuelto clave (el capital se deviene "recombinante" y el trabajo -“cognitivo"- flexible y precario). Baudrillard había hecho referencia a una fase "fractal-viral del valor" para describir un época en la que las cosas ya no desaparecen por su fin o su muerte sino por su proliferación y saturación: "ya no hay ninguna referencia, el valor irradia en todas direcciones, sin referencia a nada, por pura contigüidad- una epidemia del valor, no ley del valor, metástasis, proliferación y dispersión aleatoria” (1997: p.11). Siguiendo esta línea de inspiración, Berardi considera que diferentes capas de abstracción -la del trabajo (Marx), la de la digitalización y, finalmente, la financiera- se han superpuesto para encontrar su momento culminante en el presente semiocapitalismo ${ }^{3}$ que se consolida a través de la inscripción de "automatismos"

1 Según Berardi sería posible diferenciar dos formas de la sensibilidad: para ello retoma una distinción que permite la lengua inglesa entre sensibility y sensitivity. La sensibilidad refiere a la esfera estética, la sensitividad a la esfera erótica. La mutación conectiva hace síntoma en la disonancia que se experimenta entre ambas formas de lo sensible.

2 Berardi considera que la conjunción tiene que ver más con lo semántico y que la conexión está más vinculada a lo sintáctico, y en ese marco observa que la socialidad ha venido siendo permeada por una tendencia a la "sintactización del mundo", es decir, una "transición de la predominancia de un modo conjuntivo a la de un modo conectivo en la esfera de la comunicación humana" (2017: p.29).

3 Jean Baudrillard sentó las bases de esta conceptualización en 1976, señalando una mutación de la "economía clásica" tanto del valor económico (Marx) como del valor lingüístico (Saussure), entendidos como una relación estructural entre los términos entre sí (por sobre su funcionalidad para designar algo). Baudrillard señalaba un cambio radical: "Esta revolución consiste en que los dos aspectos del valor que se creían coherentes y eternamente ligados por una ley natural, están desarticulados, el valor referencial es aniquilado en provecho del solo juego estructural del valor. La dimensión estructural se autonomiza excluyendo a la dimensión referencial y se instaura a expensas de la muerte de aquélla. (...) El otro estadio de valor prevalece, el de la relatividad total, de la conmutación general, combinatoria y simulación. Simulación en el sentido de que todos los signos se intercambiaban entre sí en lo sucesivo sin cambiarse por algo real (y no se intercambian bien, no se intercambian perfectamente entre sí sino a condición de no cambiarse ya por algo real)." (Baudrillard, 1993: p.11-12) 
en la vida social. ${ }^{4}$ A partir de esto afirma: "El capitalismo está muerto, pero ha logrado la inmortalidad gracias a la transustanciación financiera y virtual. La matematización financiera del quehacer ordinario de la vida es la fuente de la inmortalización del cadáver del capitalismo." (2021: 48)

Estas transformaciones, además, implican la reconfiguración de las relaciones de poder (que constituyen una Gestalt, "una forma que genera formas"). "El control está en todas partes, no está políticamente centralizado" (2007: p.45) afirma Berardi al momento de hacer una caracterización del poder contemporáneo, ubicándose en el linaje deleuzeano del pasaje de las sociedades disciplinarias a las sociedades de control. Entre otras cosas, esto implica la expansión de automatismos de diverso tipo: técnicos, informáticos, financieros y lingüísticos. Esto viene de la mano del agotamiento de la era moderna y la crisis de la razón, incapaz de gobernar un mundo hipercomplejo. "Cada vez nos resulta más difícil identificar al poder con actores humanos que toman decisiones e imponen su voluntad; cada vez nos resulta más fácil hacerlo con cadenas de automatización tecnosemiótica", de ahí que se pueda "describir al poder como un proceso de construcción del automatismo cognitivo”... (2019: p.111-112)

El poder se ha separado de la subjetividad y por lo tanto asistimos al fin de la voluntad política moderna y de la ilusión del gobierno de la historia: estamos en la era de la gobernanza, es decir, ante otra dimensión en la que se vuelve evidente la tendencia a la "sintactización". El gobierno del mundo en términos tradicionales se basaba en la capacidad de elaborar significado y delimitar qué es lo relevante en los asuntos colectivos (predominio de lo semántico). Sin embargo, en el semiocapitalismo la infoesfera es cada vez más compleja y extensa, lo que hace confusa, difícil y caótica a la experiencia. Concurrimos al final del "arte de la política”, de la capacidad del príncipe de someter a la fortuna: "en la era de la computación y el caos, este arte es impotente" (2021: p.50). Esto da lugar a un conflicto entre temporalidad y posibilidad de elaboración de sentido: "La interpretación semántica ya no es posible dado que el tiempo es demasiado corto. Las decisiones deben tomarse por defecto a través de máquinas puramente sintácticas. A esto nos referimos cuando hablamos de gobernanza" (2017: p.239).

Aquí surge la pregunta por la autonomía y la posibilidad de generar espacios que puedan desvincularse del automatismo. En este contexto, también, es posible interrogar las relaciones entre multitud, red y enjambre, para explorar la posibilidad de modos de organización basados en la autonomía y la solidaridad.

4 Sostiene Berardi: "La automatización de la interacción lingüística y el reemplazo de los actos cognitivos y afectivos por secuencias y protocolos algorítmicos es la principal tendencia de la mutación en curso" (2019: p.170). 


\section{3-El general intellect}

En el inicio de la expansión de las tecnologías digitales, Internet fue vista como herramienta emancipadora por tecnólogos y académicos que vislumbraban la utopía de una "sociedad del conocimiento" en la cual podrían desplegarse sin límites las potencialidades humanas. Uno de los autores que expresa este entusiasmo es Pierre Levy, quien desarrolló la idea de "inteligencia colectiva" como "una inteligencia repartida en todas partes, valorizada constantemente, coordinada en tiempo real, que conduce a una movilización efectiva de las competencias" y cuyo fundamento es "el reconocimiento y el enriquecimiento mutuo de las personas, y no el culto de comunidades fetichizadas o hipostasiadas" (Lévy, 2004: p.19). De ahí que considere que el "ideal movilizador" de la informática ya no sería la "inteligencia artificial" (hacer máquinas que superen al hombre) sino esta forma colectiva de inteligencia (Lévy, 2007: p.140).

Este tipo de inteligencia debe ser justamente valorada: "Nadie lo sabe todo, todo el mundo sabe algo, todo el conocimiento está en la humanidad (...) La inteligencia es repartida por todas partes, es un hecho" (Lévy, 2004: p.19). Según el argumento de Levy, los "nuevos" sistemas de comunicación tienen la potencialidad de coordinar en tiempo real las inteligencias repartidas: son la clave de la realización de la inteligencia colectiva. Este entusiasmo por las potencialidades de las tecnologías digitales parece haber dejado fuera de la ecuación su incidencia en los modos de interacción, cognición y toma de decisiones. De alguna forma, retomando a Marcuse, las tecnologías aparecen como "neutrales" cuando en realidad se trata de proyectos históricos. A su vez, Levy piensa la inteligencia del conjunto como producto de la interacción consciente y autónoma de las singularidades. Lejos de la idea de una sintactización que empuja a actos ciegos y automáticos, sostiene la persistencia de una comunidad que "se traza explícitamente como objetivo la negociación permanente del orden de las cosas, de su lenguaje, del papel de cada cual, el desglose y la definición de sus objetos, la reinterpretación de su memoria" (Lévy, 2004: p.21).

Esta visión humanista y utópica del conocimientoy las comunidades surgidas del desarrollo de las tecnologías digitales de información y comunicación tuvo gran difusión y consenso. Berardi asegura que en las últimas décadas del siglo XX todo esto aparecía como un potencial de liberación y ya en el siglo XXI se hacía evidente que estaban sentadas las bases para expandir un "automatismo cognitivo global" y un "enjambre digital".

Si la metáfora del enjambre es la que mejor describe al modo de funcionamiento social contemporáneo es porque éste se produce, justamente, en base a automatismos. En otras palabras, el enjambre funciona como voluntad inconsciente que se sostiene por la fuerza de esos automatismos. Tal voluntad emerge cuando los sistemas que incorporan info y bio-máquinas se vuelven demasiado complejos para que la inteligencia y la voluntad humanas los puedan 
entender y manejar. Por eso, antes que frente a un tipo de inteligencia capaz de negociar el orden de las cosas, nos encontramos frente a la reproducción de comportamientos mecánicos. Siguiendo a Berardi, podríamos decir que no es posible una realización feliz de la "inteligencia colectiva" porque la ciberutopía olvidó y subestimó los efectos de la digitalización en la psique humana y en la subjetividad social, "ya que su ambiente tecnófilo los comprendió de manera absolutamente superficial” (Berardi, 2017: p.221). Sobre todo, los comprendió sin cuerpo: como si la mente no tuviera dimensión material (la dimensión material que no puede tolerar la aceleración e intensificación de los estímulos informáticos).

En este marco, resulta pertinente contrastar la noción de inteligencia colectiva con la de "general intellect" introducida en los Grundisse ${ }^{5}$ por Marx. Aunque en apariencia suenan parecidas, remiten a horizontes conceptuales diferentes. La primera es considerada prácticamente algo ya vigente, la segunda tiene una dimensión heurística y crítica. General intellect ha sido recuperada y ampliamente discutida por los autores vinculados al neo-operaísmo italiano (Virno, Berardi, Vercellone) ya que resulta -además de anticipatoria- muy pertinente para repensar las condiciones materiales del trabajo en el contexto actual. Paolo Virno dice que Marx había identificado el general intellect (o el saber en tanto fuerza productiva) con el capital fijo, con la "capacidad científica objetivada" (las máquinas); actualmente, el general intellect se nos aparece como "trabajo vivo" (2020: p.77). Berardi, por su parte, considera que la formulación de Marx es una "historia del futuro, y ese futuro es hoy", por lo que el general intellect no es algo ya formado sino una tarea para el siglo XXI: refiere a la "cooperación social entre trabajadores intelectuales que no están cumpliendo un diseño racional preinscripto, sino combinando fragmentos de conocimientos según proyectos intelectuales distintos (y en conflicto)" (2019: p. 217). Considerando la profunda reconfiguración que se produce en el capitalismo postfordista, Virno cuestiona la distinción que formulaba Habermas entre trabajo e interacción, ya que cristaliza una diferencia entre ámbitos que serían incomparables, pertenecientes a distintas racionalidades (instrumental y comunicativa, respectivamente). Sostener esta distinción en el contexto del semiocapitalismo se vuelve difícil, ya que el trabajo mismo es interacción e intercambio de signos (es trabajo cognitivo e implica a la comunicación).

5 Así aparecía en Marx: "La naturaleza no construye máquinas, ni locomotoras, ferrocarriles, electric telegraphs, selfacting mules. etc. Son éstos productos de la industria humana; material natural, transformado en órganos de la voluntad humana sobre la naturaleza o de su actuación en la naturaleza. Son órganos del cerebro humano creados por la mano humana, fuerza objetivada del conocimiento. El desarrollo del capital fixe revela hasta qué punto el conocimiento o knowledge social general se ha convertido en fuerza productiva inmediata, y, por lo tanto, hasta qué punto las condiciones del proceso de la vida social misma han entrado bajo los controles del general intellect y remodeladas conforme al mismo. Hasta qué punto las fuerzas productivas sociales son producidas no sólo en la forma del conocimiento, sino como órganos inmediatos de la práctica social, del proceso vital real." (K. Marx, 2007:229-230) 
El general intellect deviene un atributo del trabajo vivo en la medida en que la actividad de este último consiste, cada vez más, en prestaciones lingüísticas. (...) El proceso de trabajo no es más tímido ni taciturno, sino locuaz. La «acción comunicativa» ya no tiene más su terreno privilegiado, o exclusivo, en las relaciones ético-culturales y en la política, ni permanece fuera del ámbito de la reproducción material de la vida. Por el contrario, la palabra dialógica se inserta en el corazón mismo de la producción capitalista. (Virno, 2003: p.122)

Berardi se pregunta la razón por la que Marx elige el inglés general intellect y no la expresión alemana Allgemeine Vernunft y si bien responde que no lo sabe arriesga que es para desmarcarse de Hegel (y el devenir del espíritu). Observa cierta capacidad de anticipación de Marx respecto del presente:

Cuando Marx escribió acerca del «general intellect», esas dos palabras en inglés, tenía en mente un entorno tecnológico que aún no existía en su época. Más de cien años después, sabemos que ese entorno y esa máquina universal es la red mundial que permite hoy la continua recombinación de actos semióticos (investigación, invención, comunicación) ejecutados al mismo tiempo por agentes conscientes y sensibles desperdigados por toda la Tierra. (Berardi, 2019: p.218)

La red global de automatismos que caracteriza a la esfera del capitalismo financiero es un intento de cartografiar y someter al general intellect. La batalla que piensa Berardi tiene que ver con la autonomía del conocimiento, fundamentalmente respecto de los planteos del neoliberalismo y su paradigma económico. Considera que la "fábula" llamada Modernidad tenía como figuras emblemáticas al intelectual, el mercader y el guerrero; de forma similar piensa que los personajes centrales del general intellect son el artista, el ingeniero y el economista (2017: 213 y ss). El primero habla el lenguaje de la conjunción, el segundo el de la conexión; el economista, sin embargo, es tratado más como un sacerdote que como un científico, como un tecnócrata que separa al artista del ingeniero y trata de imponer el control económico llevando la invención al terreno de la competencia y el negocio (antes que al terreno de las necesidades del conjunto).

Todo este proceso está articulado con la idea de "cognitariado"; una "palabra híbrida" que sintetiza "dos conceptos: el de trabajo cognitivo y el de proletariado." (Berardi, 2015: p.104). La categoría se inscribe entre los constructos de Berardi para pensar cómo se produce la sujeción en un marco tecnosocial que modula las circunstancias de los trabajadores cognitivos precarizados. Los cognitarios son quienes encarnan el general intellect procesando la información que genera bienes y servicios. La forma de alienación que introduce el predominio del semiocapital se vincula con la separación de los cuerpos y el aislamiento, lo que genera 
...un sufrimiento psíquico que escapa a la definición freudiana de neurosis. Mientras esta definición se basaba en la represión del deseo, el semiocapital estimula la demanda de hiperexpresión consumista:just do it. Pánico, depresión y desactivación de la empatía: aquí encontramos el problema del cognitariado. (Berardi, 2020: p.88)

Sin embargo, para Berardi, el general intellect incluye también al cuerpo de los trabajadores cognitivos lo que impide que sea completamente reductible a la regulación de los automatismos (la "matrix"), porque además de intelecto es sensibilidad. La cognición y la sensibilidad humanas son -"como las nubes"imposibles de mapear: "La nube es la irreductibilidad de la psicoesfera al determinismo y la trazabilidad absoluta. La sensibilidad es el exceso, la plusvalía de la vida emocional que no puede ser traducida a un algoritmo." (Berardi, 2017: p.194)

Macuse logró anticipar -observa Berardi- la deriva del general intellect en El hombre unidimensional, ya que si bien la automatización podía considerarse una condición para la liberación del trabajo también era una potencial forma de dominación y control. Como se sabe, además, Marcuse fue uno de los inspiradores de las rebeliones de los años 1960 y Berardi sostiene que el movimiento estudiantil de Mayo del 68 fue la primera insurrección del general intellect. Conviene recordar la doble hipótesis en la que oscilaba la lectura marcusiana de la sociedad industrial avanzada. Por un lado, Marcuse decía que existen fuerzas y tendencias capaces de hacer estallar la sociedad pero, antes, afirmaba que la sociedad industrial avanzada "es capaz de contener la posibilidad de un cambio cualitativo para el futuro previsible." (Marcuse, 1968: p. 25). La deliberada inversión (ya que Marcuse presenta esta última tesis en primer lugar) se vuelve significativa a la luz de la deriva histórica desde los 1960 a la actualidad, en la cual esta tendencia dominadora se ha consolidado y la pregunta acerca de las dificultades para pensar alternativas duraderas -más allá de ciertas revueltas y estallidos- reactualiza aquella inquietud marcusiana. Precisamente, lo que se habría conseguido -siguiendo la lectura que Bifo hace de Marcuse- es la sumisión del general intellect, el triunfo del neoliberalismo y la aniquilación del movimiento de los trabajadores. (Berardi, 2019: p.224).

\section{4-Multitud, red, enjambre}

En el contexto del capitalismo posfordistay la crisis del Estado-nación el concepto de "multitud" adquirió vigor y vigencia, fundamentalmente como alternativa frente al concepto de "pueblo", tan pregnante en el discurso político moderno. Virno destaca que mientras este último tiene que ver con "lo Uno", la multitud tiene que ver con "los muchos", con una pluralidad que sería decisiva para el abordaje de la esfera pública contemporánea. El concepto de pueblo refiere a la división de un adentro y un afuera, mientras que en el posfordismo la multitud 
derrumba tal distinción porque su situación es "no sentirse en la propia casa". "Pueblo" fue la categoría política que se impuso en la modernidad, en tanto que en las últimas décadas sería más pertinente recuperar la de multitud (Virno, 2003:11-25). Sin duda un libro clave -publicado en 2000- fue Imperio, de Hardt y Negri, cuyo último capítulo se llamaba "La multitud contra el imperio". Cuando todo esto se vincula con el funcionamiento en red (la multitud interconectada) también se registra una especie de "entusiasmo" respecto de sus potenciales de protesta y rebelión contra el orden neoliberal.

¿Cómo se problematiza la relación entre multitud y red? La multitud es descripta por Berardi como una pluralidad de seres conscientes y sensitivos que no comparten ni su intencionalidad ni su patrón de comportamiento, es un tipo de organización social en la que "cada cual sigue su camino y la intersección de estos movimientos es lo que constituye la multitud" (2017: 240). En su carácter múltiple y su variabilidad aparece la inquietud alrededor de su capacidad de autogobierno, de participación y de desafío frente a los poderes constituidos. También la red también es una pluralidad, pero integrada por seres artificiales además de seres orgánicos. Humanos y máquinas realizan acciones en red gracias a procedimientos que hacen posible su interconexión e interoperación. Para ser parte de la red es necesario seguir esos procedimientos, que son las reglas técnicas del juego: "Dentro de una red, el lenguaje humano solo puede ser operacional cuando obedece a reglas integradas de orden sintáctico y compatibilidad semántica" (Ídem: 242).

La condición de "digital" o "interconectada" de la multitud hoy en día puede considerarse constitutiva, en la medida que -como se ha dicho en varias oportunidades- la contemporaneidad implica "habitar en un entorno digital la mayor parte de nuestras vidas." (2017: 13). Ahora bien, ese entorno digital depende fundamentalmente de las grandes corporaciones, lo que implica moderar las expectativas y apelar a la prudencia al momento de observar sus potenciales emancipatorios. El comportamiento, entonces, deja de ser aleatorio: la red preestablece caminos para quienes la usan y recorren. En tanto las máquinas tecnolingüísticas que introduce el semiocapital permean el flujo de la comunicación "el cuerpo vivo de la sociedad se convierte en un enjambre" (2017: 240).

Byung Chul-Han considera que la nueva forma de la masa es "el enjambre digital". Sin embargo, a éste "le falta un alma o un espíritu de la masa. Los individuos que se unen en un enjambre digital no desarrollan ningún nosotros. (...) No se manifiesta en una voz. Por eso es percibido como ruido." (Han, 2014: 27) Si para McLuhan el homo electronicus, el hombre de masas, es un nadie, para Han el homo digitalis es un alguien anónimo. Pero difícilmente surgiría aquí un movimiento colectivo que no fuera volátil: para Han las corrientes de indignación en Internet son shitstorms (tormentas de mierda), corrientes de afecto que no tienen la capacidad de "cuestionar las relaciones de poder". 
¿Por qué se daría esa dificultad en torno al poder? Siguiendo a Kevin Kelly (autor de The Inevitable) Berardi señala que el "ser enjambre" surge de la red: "La red es un emblema de lo múltiple. De ella sale un ser en enjambre -un ser distribuido- que disemina el ser por toda la red de manera tal que ninguna parte puede decir 'yo soy el yo'..." (Kelly citado por Berardi, 2019: 134). Este ser distribuido es un superorganismo que los organismos individuales mantienen no por medio de un gobierno consciente, sino a partir de la "incrustación de automatismos". La red -lo supra- tiene una complejidad inaccesible para cada ser individual, por lo que se inscribe en la serie de automatismos. De la misma forma, la "mente global interconectada" funciona como "mano invisible" que guía a los individuos a fusionarse con el enjambre.

En la red que da nacimiento al "ser enjambre" se oculta "el control sin autoridad". Es un tipo de funcionamiento que Kelly describe como "mentecolmena", donde las mentes individuales trabajan de manera homogénea de acuerdo al principio económico. La mente-colmena trasciende por principio la mente-abeja, así como la mente global surge de una cultura interconectada (por la unión de computadora y naturaleza): "una gran complejidad de aspecto indeterminado, gobernada por una mano invisible" (Kelly citado por Berardi 2017: 241). Así, los trabajadores precarizados del semiocapitalismo no pueden abarcar la matrix que recodifica y recombina los fragmentos de tiempo y de cognición que ellos mismos mantienen en funcionamiento. Como en la mutación que va de lo humano (conjuntivo) a lo poshumano (conectivo), la actividad cognitiva individual está cada vez más interconectada a la metamáquina y el comportamiento de enjambre responde a los automatismos tecnolingüísticos, por lo que no se puede entender desde las concepciones tradicionales de la política basadas en categorías preconectivas.

Los neohumanos conectivos se integran en un comportamiento de enjambre (...) Cada individuo es (o puede ser) agudamente consciente de su propia condición, pero ya no es capaz de gobernarla ni de modificarla, en la medida en que la interacción ya no depende de una voluntad ética o política, sino de las reglas del autómata. (2019: 119)

En este sentido, el enjambre implica un paso más allá de la red: a través de procesos de significación automatizados, la pluralidad de seres vivos sigue las reglas ahora integradas en sí a nivel sistema nervioso, recurriendo a atribuciones de significados comunes y automáticas, y a un comportamiento acorde, lo cual es también relevante para pensar el modelado del mundo emocional (Berardi, 2017; Illouz, 2019, Han, 2014a). El enjambre se establece, entonces, en el momento en que la red penetra el cuerpo social e inserta segmentos conectivos. El agente conectivo reconoce una secuencia y lleva a cabo la operación prevista por la sintaxis general, lo que elimina toda ambigüedad en el intercambio de mensajes. Para Berardi, esto transforma el concepto mismo de libertad humana 
porque las disidencias y los actos de rechazo no serán efectivos: no pueden cambiar la dirección del enjambre, ni la manera en la que su cerebro procesa la información. Es que en el enjambre lo único colectivo son los automatismos: estamos frente a la aceleración de la transformación de la "antroposfera" en un superorganismo similar a una colmena como producto del avance de la inserción de dispositivos de automatización cognitiva y la programación biogenética y psicofarmacológica del cerebro humano (Berardi, 2019: 139).

Siguiendo al biólogo Eugene Thacker, Berardi afirma que, aunque la colectividad implica conectividad, esto no sucede a la inversa. La colectividad es una relación de cuerpos que comparten un entendimiento analógico, que negocian continuamente sobre la relevancia semántica de sus intercambios lingüísticos y sobre el significado de sus interacciones, en condiciones de inclusión afectiva. El enjambre, en cambio, es un cuerpo conectivo, sin colectividad afectiva consciente. Como sistema conectivo, no crea significado/ conocimiento -algo que sí sucede en la conjunción, bajo cuya condición tiene lugar la colectividad: los actos de conjunción no presuponen significado, sino que lo crean. Lo que sucede en la conectividad, en cambio, es "mero reconocimiento sintáctico" (Berardi, 2017: 244). En la funcionalidad maquínica, la comunicación implica interoperatividad: "sólo los segmentos que con anterioridad se hicieron lingüísticamente compatibles pueden interactuar" (Ídem: 245).

Además, la proliferación de dispositivos tecnológicos que transforman la experiencia del mundo (como la realidad aumentada) comporta que el propio mundo en cuanto experiencia y proyección se vacíe y se reemplace "por una experiencia uniformada y simulada". Este tipo de experiencia es la que define al enjambre porque el proceso de creación conectiva es una estandarización de la cognición, la percepción y el comportamiento "basada en la inserción de automatismos tecnolingüísticos dentro de la comunicación humana $y$, por ende, de la mente conectiva" (Ídem). El cableado conectivo permanente de las interacciones humanas (el sistema tecnolingüístico de intercambio permanente, la separación del "lenguaje vivo", los interlocutores cada vez menos actores de su propia interacción y la captura de la comunicación en el "enjambre electrónico") produce un reemplazo de la experiencia viva y su simulación por estímulos estandarizados y registrados.

Este escenariolepermite anticipar a Berardiquela modificación delhardware neuronal a través de la inserción de dispositivos técnicos, de nanoprótesis, de modificadores y de potenciadores de programación neuronal en el sistema nervioso llevaría hacia un tecno-totalitarismo o neurototalitarismo, algo así como la traducción política del efecto enjambre.

Por otra parte, para Berardi la transición hacia el enjambre involucra una especie de estallido del yo, expresado en el florecimiento de la economía de la psicofarmacología que acompaña ese devenir. La aceleración del flujo de infoestimulación, el efecto multitasking y la presión competitiva ligada a la capacidad de seguir el ritmo de la infoesfera están en la base de las enfermedades 
que afectan la capacidad de mantener la atención y de producir un flujo de enunciación constante: la densidad de la infoesfera saturó la receptividad de la psicoesfera. Esta sobrecarga, que hace incapaces a los actores humanos de gobernar la complejidad sistémica a nivel social y tecnológico, termina por producir una desconexión del cuerpo social y el cerebro social. Así, se acentúa la escisión entre sensibilidad e intelecto y "la conciencia social se ve amenazada y se fragmenta de tal manera que la rabia contra la explotación se convierte en frustración y autodesprecio. Los procesos de subjetivación no encuentran el camino hacia la autonomía social" (2017: 249).

¿Cómo podrían producirse, entonces, modos de organización basados en la autonomía y la solidaridad? Berardi ve una posibilidad en el desacoplamiento del general intellect del enjambre conectado a nivel "tecnoneuronal" y su reunión con su propio cuerpo sensible "para crear las condiciones de independencia del conocimiento respecto a la matrix y de singularidad de la experiencia" (2017: 336).

Berardi observa que, cuando no está regulada por convenciones compartidas, la existencia social se convierte en una nube: "en un vapor de agua que se mueve incesantemente, se condensa, se disuelve, cambia de forma y de grado de densidad". Pero la vida fragmentada "se recodifica, se fractaliza y se recombina a través de las reglas de conexión inscriptas en las interfaces técnicas de la comunicación social". Esta tensión entre la irreductibilidad de "la nube" y el mapeo de "la matrix" abre una posibilidad de desregulación, desautomatización e invención, como producto del general intellect ya que éste tiene un cuerpo que no es sólo intelecto sino también sensibilidad (2015: 105) y la "vida emocional" no se puede traducir a una serie de algoritmos (aunque pueda ser afectada por éstos). Aquí resulta pertinente la vinculación con los aportes que puede hacer el psicoanálisis, ya que si bien vivimos en una era del "yo cuantificado" el "psiquismo humano es un proceso que integra elementos que no son digitalizables" (Dessal, 2019: 148).

\section{A modo de cierre}

El diagnóstico de Bifo en Fenomenología del fin (2017) y Futurabilidad (2019) tiene un tono sombrío. A medida que las energías intelectuales de la sociedad son capturadas por la red de la abstracción financiera, el trabajo cognitivo se ve sujeto a la ley abstracta de valor y la comunicación humana se transforma en una interacción abstracta entre agentes digitales sin cuerpo. Esta separación respecto del cuerpo social provoca "la subsunción del general intellect en el reino corporativo de la abstracción" y de este modo "está privando a la comunidad viva de inteligencia, comprensión y emoción afectiva” (2019: 155-156). Ese diagnóstico está atravesado por la interrogación acerca de la "incapacidad" colectiva para generar formas de solidaridad que lleven a producir una ruptura 
y potenciar la autonomía. Los cognitarios no parecen tener un fuerte potencial de autoorganización.

Algunas expectativas diferentes aparecen en su reciente La segunda venida (2021) en el que pone sobre la mesa una reelaboración de la consigna "socialismo o barbarie" de los sesenta en una más radical "el comunismo o la extinción”, pero pensando en un comunismo muy diferente al de 1917, vinculado a la autoorganización de los cognitarios, el despliegue de los potenciales y la reorientación de la semioproducción en función de la satisfacción de las necesidades sociales. Para Berardi, "la tarea cultural y política del futuro es reavivar la intensidad de la sensibilidad corporal y desvincular la potencia del general intellect del aparato tecno-económico" (2017:315). Esto implicaría, entre otros desafíos, salirse de la Gestalt que configuran las relaciones de poder.

\section{Referencias bibliográficas}

Baudrillard, J. (1993), El intercambio simbólico y la muerte. Caracas: Monte y Ávila.

Baudrillard, J. (1997). La Transparencia del mal. Ensayo sobre los fenómenos extremos. Barcelona: Anagrama.

Berardi, F. (2007). Generación Post-Alfa: patologías e imaginarios en el semiocapitalismo. Buenos Aires: Tinta Limón.

Berardi, F. (2014). La sublevación. Buenos Aires: Hekht.

Berardi, F. (2015). La fábrica de la infelicidad. Nuevas formas de trabajo y movimiento global. Madrid: Tinta Limón. (orig. 2003)

Berardi, F. (2017). Fenomenología del fin. Sensibilidad y mutación conectiva. Buenos Aires: Caja Negra.

Berardi, F. (2019). Futurabilidad. La era de la impotencia y el horizonte de la posibilidad. Buenos Aires: Caja Negra.

Berardi, F. (2020). "Subjetivación cognitaria”, en AV, Neo-operaísmo, Buenos Aires: Caja Negra.

Berardi, F. (2021), La segunda venida. Neorreaccionarios, guerra civil global y el día después del Apocalipsis, Buenos Aires: Caja Negra.

Deleuze, G. (1990). "Postdata sobre las sociedades de control", en Babel, № 21.

Habermas y otros (2018), Filosofía radical. Conversaciones con Marcuse, México: Gedisa.

Han, Byung-Chul (2014). En el enjambre, Barcelona: Herder.

Han, Byung-Chul (2014a), Psicopolítica, Barcelona: Herder.

Hardt, A. y T. Negri (2012). Imperio. Buenos Aires: Paidós.

Illouz, E. (2019), Capitalismo, consumo y autenticidad. Las emociones como mercancía, Buenos Aries: Katz.

Lévy, P. (2004). Inteligencia colectiva: por una antropología del ciberespacio. Disponible en: http://inteligenciacolectiva.bvsalud.org

Lévy, Pierre (2007), Cibercultura. La cultura en la sociedad digital, Barcelona: Anthropos.

Marcuse, H. (1969). El hombre unidimensional. Ensayo sobre la ideología de la sociedad industrial avanzada, Barcelona: Seix Barral.

Marx, K. (2007), Elementos fundamentales para la crítica de la economía política (Grundisse) 1857-1858, México: Siglo XXI. 
Sadin, Éric (2018). La silicolonización del mundo. La irresistible expansión del liberalismo digital. Caja negra: Buenos Aires.

Van Dijck, José (2016). La cultura de la conectividad. Una historia crítica de las redes sociales. Siglo XXI: Buenos Aires.

Virno, P. (2003), Gramática dela multitud. Para un análisis de las formas de vida contemporánea, Buenos Aires: Colihue.

Virno, P. (2020), “General Intellect”, en AV, Neo-operaísmo. Buenos Aires: Caja Negra. 